\title{
Allogeneic Double Negative T Cells
}

National Cancer Institute

\section{Source}

National Cancer Institute. Allogeneic Double Negative T Cells. NCI Thesaurus. Code C147134.

A population of healthy, donor-derived CD4 and CD8 double-neg ative T-lymphocytes (DNTs), with potential immunomodulating and anti-leukemic activities. The DNTs are expanded ex vivo in order to enhance their tumor destroying potential. Upon administration of the allogeneic DNTs (DNT-UHN-1), the receptors NKG2-D type II integral membrane protein (KLRK1; NKG2D) and DNAX accessory molecule 1 (cluster of differentiation 226; CD226; DNAM-1) expressed on the DNTs recognize and bind to their cognate ligands expressed on leukemia cells. Upon binding, the DNTs release interferongamma (IFN-g), thereby destroying the tumor cells. DNTs derived from peripheral blood of healthy donors appear to be effective against certain types of tumor cells, including leukemia cells, and do not attack normal hematopoietic cells. NKG2D, a member of the CD94/NKG2 family of C-type lectin-like receptors, and DNAM-1, a member of the immunog lobulin superfamily containing 2 Ig-like domains of the $\mathrm{V}$-set, play a key role in natural killer cell (NK)-mediated tumor cell killing. Certain tumor cells express higher levels of NKG2D and DNAM-1 ligands on their surfaces, thereby increasing their susceptibility to DNT-mediated cell lysis. 